\title{
Prevenção de Acidentes na Indústria
}

\author{
Accident Prevention in Industry
}

Jéssica Márcia Silva Barizon ${ }^{\dagger *}$, Enilson Salino Braga

Como citar esse artigo. Barizon,

JMS; Braga, ES. Prevenção de

Acidentes na Indústria. Revista Teccen. 2020 Jan./Jun.; 13 (1): xx-xx.

\author{
Resumo
}

Desde o século XVIII com o início da Revolução Industrial, muitos acidentes de trabalho ocorreram nas indústrias dos mais variados ramos de negócio. Os trabalhadores sofriam muito com as péssimas condições de trabalho, por mais que o ritmo acelerado de produção trouxesse muita lucratividade para os empresários da época, muitos trabalhadores, inclusive mulheres e crianças tiveram que se submeter aos ambientes de trabalho extremamente perigosos e insalubres e que poderiam oferecer algum tipo de risco para a sua saúde e segurança. Este trabalho tem como objetivo demonstrar a importância da prevenção de acidentes na indústria e porque a segurança do trabalho deve ser estabelecida como um fator primordial na execução de qualquer atividade, de forma que o trabalhador não exponha sua integridade física. A prevenção de acidentes pode promover diversos benefícios, além de proteger o trabalhador dos riscos de acidentes, ela possibilita o aumento da lucratividade e a melhora da imagem da empresa perante a sociedade, pois o setor industrial apresenta atualmente um dos maiores índices de acidentes do trabalho, o que pode impactar negativamente para o crescimento econômico. Toda e qualquer empresa só tem a ganhar com uma boa política de prevenção de acidentes, pois quando a segurança é colocada em primeiro lugar, o número de ocorrências de acidentes é reduzido e consequentemente reduzem-se os impactos financeiros gerados com as despesas previdenciárias e quedas de produção. Palavras-Chave: : Prevenção; Acidentes de Trabalho; Indústria; Segurança do Trabalho; Benefícios.

\begin{abstract}
Since the eighteenth century with the beginning of the Industrial Revolution, many accidents at work occurred in the industries of the most varied branches of business. The workers suffered a lot from the bad working conditions, even though the fast pace of production brought a lot of profitability for the entrepreneurs of the time, many workers, including women and children, had to submit to extremely dangerous and unhealthy work environments that could offer some kind of risk to your health and safety. This work aims to demonstrate the importance of accident prevention in the industry and why work safety must be established as a primary factor in the performance of any activity, so that the worker does not expose his physical integrity. Accident prevention can promote several benefits, in addition to protecting workers from the risks of accidents, it makes it possible to increase profitability and improve the company's image before society, as the industrial sector currently has one of the highest rates of occupational accidents., which can negatively impact economic growth. Any and all companies can only benefit from a good accident prevention policy, because when safety is placed first, the number of accident occurrences is reduced and consequently the financial impacts generated by social security expenses and falls are reduced of production.

Keywords: Prevention; Work Accidents; Industry; Work Safety; Benefits.
\end{abstract}

\section{Introdução}

Com o início da Revolução Industrial na segunda metade do século XVIII, muitas mudanças ocorreram nos processos produtivos na Inglaterra. Este novo modelo de produção industrial começou a se espalhar por grande parte do hemisfério norte, possibilitando a produção em larga escala nos mais diversos ramos de negócio.

Muitos impactos positivos puderam ser obtidos com o novo modelo de produção, além de promover um grande crescimento econômico, pode-se destacar a chegada da máquina a vapor, o que contribuiu fortemente para o aumento da capacidade produtiva. Porém, o ritmo de produção acelerado provocou muitos impactos negativos, entre eles o aumento da jornada de trabalho para até 16 horas, utilização de mão-de-obra infantil, condições de trabalho inseguras e inadequadas, lesões por esforços repetitivos (LER), exposição a riscos nocivos à saúde, como ruídos, poeiras, gases, vapores e calor excessivo, aumentando drasticamente o número de acidentes e de problemas de saúde relacionados ao trabalho.

\footnotetext{
Afiliação dos autores:

${ }^{\dagger}$ Discente de pós-graduação, Universidade de Vassouras, Vassouras - RJ, Brasil

* Docente, Universidade de Vassouras, Vassouras - RJ, Brasil

* Email para correspondência: jessica.barizon@live.com
} 


\section{Segundo Hobsbawm (2012):}

A partir da metade do século XVIII, o processo de acumulação de velocidade para partida é tão nítido que historiadores mais velhos tenderam a datar a revolução industrial de 1760. Mas uma investigação cuidadosa levou a maioria dos estudiosos a localizar como decisiva a década de 1780 e não a de 1760 , pois foi então que, até onde se pode distinguir, todos os índices estatísticos relevantes deram uma guinada repentina, brusca e quase vertical para a "partida". A economia, por assim dizer, voava. (Hobsbawm, 2012)

Conforme ilustrado na figura 1 abaixo, o filme tempos modernos faz uma dura crítica às péssimas condições de trabalho aos quais os trabalhadores eram expostos durante a revolução industrial:

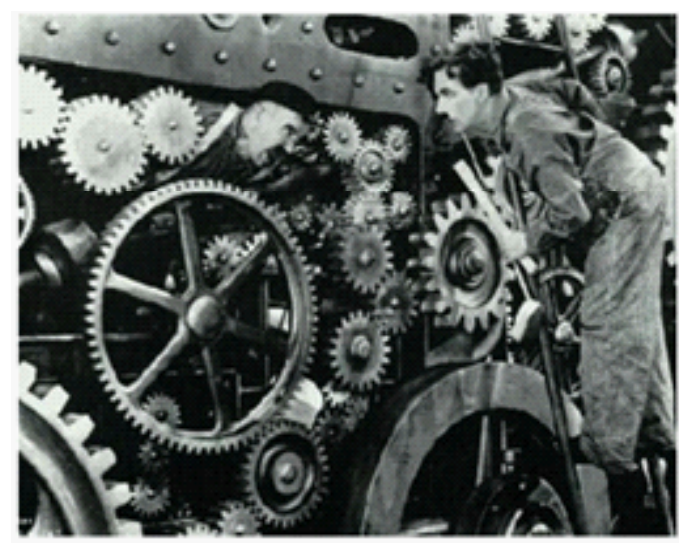

Figura 1. Trabalhador acidentado em meio às máquinas

Fonte: Cena do filme "Tempos modernos" de Charles Chaplin. EUA. (1936)

\section{Conforme Barbosa Filho (2001) destaca:}

Ao lado das vantagens obtidas com a introdução da maquinaria, igualmente afloraram aspectos negativos. Ritmos excessivos de produção, manutenção deficiente - por que não dizer precária - e a existência de partes móveis, aquecidas e de brusco movimento, arestas cortantes, além dos sistemas de transmissão de força e os elementos de operação propriamente ditos, causaram e ainda causam muitos acidentes entre os trabalhadores. (Barbosa Filho, 2018)

Diante daquele cenário assustador, os trabalhadores passaram a se mobilizar e sindicatos começaram a ser criados com o objetivo de melhorar as condições de trabalho.

Após muitos conflitos, as primeiras leis de proteção ao trabalhador foram criadas e a adoção de medidas e procedimentos de segurança se tornaram cada vez mais presentes nas indústrias, possibilitando assim, que as atividades fossem realizadas com mais segurança e a ocorrência de acidentes de trabalho fosse reduzida. Barbosa Filho (2001) destaca os pontos positivos e negativos obtidos com o novo modelo de produção:

...Com a introdução da mecanização e de sua evolução alcançou patamares de volume e de velocidade de produção que permitiram níveis de produtividade jamais vistos. É inegável o impacto que as máquinas causaram sobre a forma de produzir. Por um lado, reduziram o esforço empregado diretamente pelo trabalhador na produção e ampliaram a capacidade produtiva. E, poroutro, estabeleceramritmosedemandaram habilidades crescentes. De tal maneira foram as mudanças introduzidas que não tardaram a surgir reações contrárias à sua utilização. (Barbosa Filho, 2018)

A segurança do trabalho passou a ser introduzida no Brasil com a criação da CLT, durante o governo de Getúlio Vargas, iniciando-se o processo de direitos dos trabalhadores (Decreto-Lei n. 5.452, 1943), mas somente em 1978 o Ministério do Trabalho e Emprego aprovou as Normas regulamentadoras através da Portaria 3.214/78.

De acordo com a Portaria 3.214 de 08 de junho de 1978 do Ministério do Trabalho são direitos dos trabalhadores urbanos e rurais, além de outros que visem à melhoria de sua condição social a redução dos riscos inerentes ao trabalho, por meio de normas de saúde, higiene e segurança. (Portaria n. 3.214, 1978)

Segundo os dados da Organização Internacional do Trabalho (OIT), estima-se que a cada 15 segundos 160 trabalhadores sofram algum tipo de acidente do trabalho e que a cada 15 segundos um trabalhador vá a óbito no mundo devido a ocorrência de acidentes ou de doença do trabalho. Ainda de acordo com a (OIT, 2019), calcula-se que de um total de 2,34 milhões de acidentes de trabalho mortais por ano, apenas $321 \mathrm{mil}$ estão diretamente relacionadas a acidentes e as restantes 2,02 milhões de mortes são ocasionadas por doenças relacionadas ao trabalho.

Conforme dados do Observatório Digital de Saúde e Segurança do Trabalho do Ministério Público do Trabalho (OSST, 2019), foram registrados entre o ano de 2012 e 2018, 4,26 milhões de acidentes de trabalho no Brasil, gerando um custo de aproximadamente 28,8 milhões de reais em benefícios para os acidentados e o número de afastamento nas empresas chegou a ser

Quadro 1. Quantidade de acidentes do trabalho, por situação do registro e motivo, segundo a Classificação Nacional de Atividades Econômicas (CNAE), no Brasil - 2015/2017

\begin{tabular}{|c|c|c|c|c|c|c|c|c|c|c|c|c|c|c|c|c|c|c|}
\hline \multirow{5}{*}{ CUAE } & \multicolumn{18}{|c|}{ QUAAITDADE DE ACIDEUTES DO TRABALHO } \\
\hline & \multirow{3}{*}{\multicolumn{3}{|c|}{ Total }} & \multicolumn{12}{|c|}{ Com CAT Regigradada } & \multirow{3}{*}{\multicolumn{3}{|c|}{ Sem CAT Registrada }} \\
\hline & & & & \multirow{2}{*}{\multicolumn{3}{|c|}{ Total }} & \multicolumn{9}{|c|}{ Motivo } & & & \\
\hline & & & & & & & \multicolumn{3}{|c|}{ Tipico } & \multicolumn{3}{|c|}{ Trajeto } & \multicolumn{3}{|c|}{ Doença do Trabalho } & & & \\
\hline & 2015 & 2015 & 2017 & 2015 & 2016 & 2017 & 2015 & 2016 & 2017 & 2015 & 2016 & 2017 & 2015 & 2015 & 2017 & 2015 & 2016 & 2017 \\
\hline TAL & 22.379 & 585.626 & 9.405 & 507.753 & 478.099 & 450.614 & 385.646 & 355.560 & 340228 & $\left.106.721\right|_{1}$ & 108.552 & 100.685 & 15306 & 13927 & 9.700 & 114.626 & 107.587 & 98791 \\
\hline
\end{tabular}

Fonte: Anuário Estatístico de Acidentes do Trabalho - Previdência Social (2017) - Adaptado 
superior a 335 milhões nas empresas.

De acordo como anuário estatístico de acidentes do trabalho da Previdência Social (AEAT, 2017), no quadro 1, somente no ano de 2017 houve aproximadamente 550 mil acidentes do trabalho no Brasil.

Ainda de acordo com o Anuário Estatístico da Previdência Social, é possível verificar na tabela 1 que entre 2015 e 2017 foram concedidos aproximadamente 700 mil benefícios acidentários no Brasil. podem trazer dificuldades financeiras para a atuação das empresas ou mesmo culminar com a ruína destas. (Barbosa Filho, 2018)

A prevenção de acidentes possibilita também uma maior motivação por parte dos trabalhadores devido ao ambiente de trabalho estar com condições mais seguras e adequadas para a realização das atividades e os procedimentos de segurança bem estabelecidos.

Sell (2002) afirma que:

Tabela 1. Quantidade de benefícios concedidos, por clientela, segundo os grupos de espécies - 2015/2017.

\begin{tabular}{|c|c|c|c|c|c|c|c|c|c|}
\hline \multirow{4}{*}{$\begin{array}{l}\text { GRUPOS DE } \\
\text { ESPÉCIES }\end{array}$} & \multicolumn{9}{|c|}{ QUANTIDADE DE BENEFICIOS CONCEDIDOS } \\
\hline & \multirow{2}{*}{\multicolumn{3}{|c|}{ Total }} & \multicolumn{6}{|c|}{\begin{tabular}{|c|c|} 
& Clientela \\
\end{tabular}} \\
\hline & & & & \multicolumn{3}{|c|}{ Urbana } & \multicolumn{3}{|c|}{ Rural } \\
\hline & 2015 & 2016 & 2017 & 2015 & 2016 & 2017 & 2015 & 2016 & 2017 \\
\hline TOTAL & 4.344 .701 & 5.132 .451 & 4.995 .623 & 3.546 .427 & 4.245 .154 & 4.104 .488 & 798.274 & 887.297 & 891.135 \\
\hline Acidentários & 222.450 & 251.911 & 220.651 & 210.652 & 239.293 & 210.593 & 11.798 & 12.618 & 10.058 \\
\hline $\begin{array}{l}\text { Aposentadoria por } \\
\text { Invalidez }\end{array}$ & 8.782 & 9.220 & 9.319 & 8.236 & 8.667 & 8.717 & 546 & 553 & 602 \\
\hline Pensão Por Morte & 368 & 393 & 298 & 360 & 386 & 295 & 8 & 7 & 3 \\
\hline Aurilios & 213.300 & 242.298 & 211.034 & 202.056 & 230.240 & 201.581 & 11.244 & 12.058 & 9.453 \\
\hline Doença & 196.761 & 223.668 & 191.118 & 185.998 & 212.209 & 182.290 & 10.763 & 11.459 & 8.828 \\
\hline Acidente & 16.399 & 18.513 & 19.764 & 15.918 & 17.914 & 19.139 & 481 & 599 & 625 \\
\hline Suplementar & 140 & 117 & 152 & 140 & 117 & 152 & - & - & - \\
\hline
\end{tabular}

Este trabalho tem como objetivo demonstrar a importância da prevenção de acidentes na indústria e como a prevenção de acidentes pode contribuir positivamente com o sucesso da empresa, trazendo diversos benefícios.

Além de se reduzir as perdas humanas, podese citar também como benefício o aumento da lucratividade, a melhora da imagem da empresa perante seus acionistas e a sociedade, pois as empresas que demonstram preocupação com a segurança dos seus funcionários tendem a ser bem vistas por todas as partes interessadas.

Segundo Barbosa Filho (2001):

Uma das maiores preocupações do setor produtivo é a ocorrência de um evento ou sequência de eventos de tal magnitude capaz de comprometer a continuidade de suas atividades. Sinistros como incêndios, inundações e acidentes envolvendo trabalhadores, atingindo não apenas estes, mas as instalações, a maquinaria e o meio ambiente próximo ou circundante podem ensejar, além dos danos humanos, perdas materiais traduzidas em valores e imateriais, como imagem institucional e sentimentos alheios, de mais difícil mensuração. Enfim, prejuízos de diversas ordens
As empresas que sujeitam seus trabalhadores a condições inadequadas perdem em termos de qualidade, produtividade, competitividade e imagem perante a sociedade. Trabalhadores em más condições de trabalho não contribuem na melhoria de processo e produtos, reduzem sua disposição para o trabalho, não têm comprometimento com a empresa por não se sentirem parte do processo. (Sell, 2002)

\section{Classificação Nacional de Atividade Econômica (CNAE) para a Indústria}

A Classificação Nacional de Atividade Econômica (CNAE) tem como objetivo identificar as atividades econômicas desenvolvidas por uma empresa através de códigos, e assim, classificá-la de acordo com o seu segmento de atuação. Esta classificação permite melhorias na gestão de tributos e suporte a decisões administrativas a níveis municipal, estadual e federal.

De acordo com o quadro 2 , os códigos utilizados para a identificação de atividades econômicas realizadas nos setores industriais são: 
Quadro 2. Conversão de CNAE para SAE 2.0.

\begin{tabular}{|c|c|}
\hline SETOR DE ATIVIDADE ECONOMMICA & CNAE 2.0 \\
\hline \multicolumn{2}{|l|}{ INDÚSTRIA } \\
\hline EXTRATIVA & $5,6,7,8,9$ \\
\hline \multicolumn{2}{|l|}{ TRANSFORMAÇÃO } \\
\hline Produtos Alimentícios e Bebidas & 10,11 \\
\hline Produtos Têxteis e Artigo de Vestuário & $13,14,15$ \\
\hline Fabricação de Papel e Celulose & 17 \\
\hline Petróleo, Biocombustiveis e Coque & 19 \\
\hline Produtos Químicos & 20,21 \\
\hline Artigos de Borracha e Material Plástio & 22 \\
\hline Produtos de Minerais Não Metálicos & 23 \\
\hline Metalurgia & 24 \\
\hline Fabricaçãp de Produtos de Metal & 25 \\
\hline Fabricação de equipamentos eletrônicos e ópticos & 26 \\
\hline Fabricação de Máquias e Equipamentos & 27,28 \\
\hline Fabricação de Veículos e Equipamentos de Transporte & 29,30 \\
\hline Outras Indústrias de Transformação & $12,16,18,31,32,33$ \\
\hline
\end{tabular}

Fonte: Anuário Estatístico da - Previdência Social (2017) - Adaptado

Quadro 3. Classificação Nacional de Atividade Econômica (CNAE 2.0).

\begin{tabular}{|c|c|c|c|c|}
\hline \multicolumn{3}{|c|}{ Código CNAE 2.0 } & \multirow{2}{*}{ DESCRIÇÃ̃o } \\
\cline { 1 - 3 } Seção & Divisão & Grupo & Classe & \\
\hline C & & & & INDÚSTRIA DE TRANSFORMAÇ̃̃o \\
\hline & 10 & & & FABRICAÇÃo DE PRODUTOS ALIMENTíCIOS \\
\hline & & 10.1 & & Abate e fabricação de produtos de came \\
\hline & & & $10.12-1$ & Abate de suínos, aves e outros pequenos animais \\
\hline
\end{tabular}

Fonte: Anuário Estatístico da - Previdência Social (2017) - Adaptado

Para a indústria de abate de suínos, aves e outros pequenos animais, por exemplo, utiliza-se o código CNAE 10.12, conforme é possível verificar no quadro 3 abaixo do Anuário Estatístico da Previdência Social.

Ao se identificar o código CNAE de determinado setor de atividade econômica é possível verificar o número de acidentes ocorridos em um determinado período.

De acordo com o quadro 4, verifica-se que ocorreram entre 2015 e 2017 aproximadamente 30 mil acidentes do trabalho na indústria de abate de suínos, aves e outros pequenos animais.

\section{Acidentes de trabalho na Indústria}

Dentre as principais causas de acidentes de trabalho na indústria podem-se destacar as seguintes: não cumprimento das normas e procedimentos, uso inadequado de ferramentas e/ou equipamentos de proteção, choques elétricos, movimentos repetitivos, cansaço e fadiga, não conhecimento dos riscos existentes no local de trabalho, quedas em alturas, dentre outros.

Segundo (Asfahl, 2005) cerca de 18\% das notificações apresentadas pela OSHA ao setor industrial estão relacionadas ao descumprimento das normas e regulamentações técnicas e que as "condições perigosas mecânicas" devem ser controladas por dispositivos de proteção.

Conforme é possível verificar na tabela 2 do Anuário Estatístico da Previdência Social, estima-se que entre os anos de 2015 e 2017 de um total de 1 milhão e 700 mil acidentes do trabalho, aproximadamente 1 milhão e 100 mil ocorreram somente na indústria extrativa e de transformação, ou seja, cerca de $62 \%$ dos acidentes do trabalho registrados no Brasil ocorreram na Indústria.

Estes números mostram a grande necessidade de investimentos na área de Saúde e Segurança do 
Quadro 4. Quantidade de acidentes do trabalho, por situação do registro e motivo, segundo a Classificação Nacional de Atividades Econômicas (CNAE), no Brasil - 2015/2017.

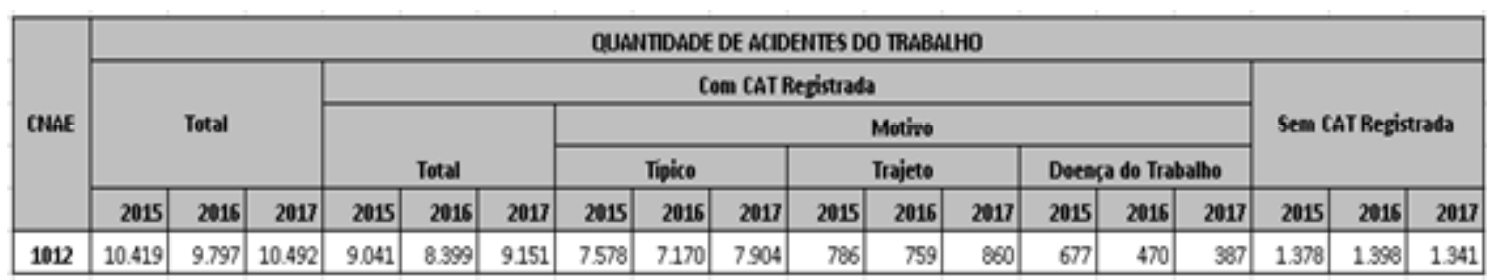

Fonte: Anuário Estatístico da - Previdência Social (2017) - Adaptado

Tabela 2. Quantidade de acidentes do trabalho, por situação de registro e motivo, segundo o Setor de Atividade Econômica - 2015/2017.

\begin{tabular}{|c|c|c|c|c|c|c|c|}
\hline \multirow{4}{*}{ SETOR DE AIIVIDADE ECONŌMICA (1) } & \multirow{4}{*}{ Anos } & \multicolumn{6}{|c|}{ QUANTIDADE DE ACIDENTES DO TRABALHO } \\
\hline & & \multirow{3}{*}{ Total } & \multicolumn{4}{|c|}{ Com CAI Registrada } & \multirow{3}{*}{$\begin{array}{c}\text { Sem CAI } \\
\text { Registrada }\end{array}$} \\
\hline & & & \multirow{2}{*}{ Total } & \multicolumn{3}{|c|}{ Motivo } & \\
\hline & & & & Típico & Trajeto & Doença do Trabalho & \\
\hline \multirow{3}{*}{ TOTAL } & 2015 & 622.379 & 507.753 & 385.646 & 106.721 & $\begin{array}{r}15.386 \\
\end{array}$ & 114.626 \\
\hline & 2016 & 585.626 & 478.039 & 355.560 & 108.552 & 13.927 & 107.587 \\
\hline & 2017 & 549.405 & 450.614 & 340.229 & 100.685 & 9.700 & 98.791 \\
\hline \multirow{3}{*}{ Indústria } & 2015 & 236.307 & 207.459 & 170.122 & 30.260 & 7,077 & 28.849 \\
\hline & 2016 & 207.484 & 181.502 & 146.769 & 28.969 & 5.764 & 25.982 \\
\hline & 2017 & 189.814 & 166.659 & 136.381 & 26.315 & 3.963 & 23.155 \\
\hline \multirow{3}{*}{ Indústria de transformaçấo } & 2015 & 170.424 & 150.107 & 122.396 & 21.603 & 6.108 & 20.317 \\
\hline & 2016 & 151.386 & 132.948 & 106.968 & 21.020 & 4.960 & 18.438 \\
\hline & 2017 & 141.424 & 124.480 & 101.807 & 19.455 & 3.218 & 16.944 \\
\hline
\end{tabular}

Fonte: Anuário Estatístico da Previdência Social (2017)

Trabalho não só na Indústria, mas em todos os setores de Atividade Econômica do país.

\section{Importância da Comissão Interna de Prevenção de Acidentes (CIPA)}

O objetivo da CIPA é prevenir os acidentes e as doenças ocasionadas no ambiente de trabalho, de forma que as atividades a serem executadas não comprometam a vida e a saúde dos trabalhadores, preservando, assim, a integridade física dos mesmos.

Cabe a CIPA identificar os riscos inerentes ao processo e elaborar juntamente com a participação do SESMT e do maior número de trabalhadores possíveis, o mapa de risco da empresa de forma que o tipo e o grau de riscos sejam fáceis de serem identificados e melhor controlados, cabe também a CIPA realizar um plano de trabalho que promova ações preventivas à fim de se solucionar problemas relacionados a segurança e saúde dos trabalhadores. A CIPA deve realizar reuniões frequentemente com o objetivo de se debater a respeito dos riscos presentes no ambiente de trabalho e definir metas para que estes riscos sejam controlados ou eliminados.

Anualmente a CIPA deve promover junto ao SESMT a Semana Interna de Prevenção de Acidentes do Trabalho (SIPAT) com o intuito de se conscientizar os trabalhadores sobre a importância da segurança do trabalho na realização de suas atividades.

De acordo com a com a NR 5 (2011):

A Comissão Interna de Prevenção de Acidentes - CIPA - tem como objetivo a prevenção de acidentes e doenças decorrentes do trabalho, de modo a tornar compatível permanentemente o trabalho com a preservaçãodavidaeapromoçãodasaúdedotrabalhador.(ENIT,2011)

Com isso, verifica-se a grande importância da CIPA para a prevenção de acidentes na Indústria. A CIPA permite aos seus integrantes a autonomia de criar ações preventivas em busca de maior proteção aos trabalhadores, visto que muita das vezes os integrantes da CIPA são os colaboradores que lidam diretamente com as atividades operacionais e que contém mais riscos de acidentes.

Visão Geral da Norma Regulamentadora 9 - Programa de Prevenção de Riscos Ambientais (PPRA) 
A NR-9 visa através da implementação do Programa de Prevenção de Riscos Ambientais preservarem a saúde e a integridade dos trabalhadores por meio da antecipação, reconhecimento, avaliação e controle da ocorrência dos riscos de ambientais que possam existir no ambiente de trabalho levando em conta a proteção do meio ambiente e dos recursos naturais.

Cabe ao empregador sempre informar aos trabalhadores sobre os riscos ambientais existentes no local de trabalho e como preveni-los de forma a controlálos, visando sempre à proteção dos trabalhadores.

A obrigação do empregador é fornecer todos os equipamentos de proteção individual necessários para proteger o trabalhador e é dever do trabalhador utilizar e conservar corretamente os seus EPIs.

Para a elaboração do PPRA consideram-se como riscos ambientais os agentes químicos, físicos e biológicos presentes no ambiente laboral e que dependendo da concentração e tempo de exposição possam ser prejudiciais à saúde.

Segundo ENIT (2017), na NR-9, itens 9.1.5.1, 9.1.5.2 e 9.1.5.3 consideram agentes físicos químicos e biológicos os seguintes agentes:

Consideram-se agentes físicos as diversas formas de energia a que possam estar expostos os trabalhadores, tais como: ruído, vibrações, pressões anormais, temperaturas extremas, radiações ionizantes, radiações não ionizantes, bem como o infra-som e o ultra-som. Consideram-se agentes químicos as substâncias, compostos ou produtos que possam penetrar no organismo pela via respiratória, nas formas de poeiras, fumos, névoas, neblinas, gases ou vapores, ou que, pela natureza da atividade de exposição, possam ter contato ou ser absorvidos pelo organismo através da pele ou por ingestão. Consideram-se agentes biológicos as bactérias, fungos, bacilos, parasitas, protozoários, vírus, entre outros. (ENIT, 2017)

Segundo ENIT (2017), na NR-9, item 9.2.1, determina-se que para a implementação do PPRA é de extrema importância que seja seguida a seguinte estrutura: a) planejamento anual com estabelecimento de metas, prioridades e cronograma

b) estratégia e metodologia de ação;

c) forma do registro, manutenção e divulgação dos dados;

d) periodicidade e forma de avaliação do desenvolvimento do PPRA. (ENIT, 2017)

É necessário definir o cumprimento do PPRA como uma atividade constante na empresa para que a implementação do mesmo seja eficaz e, assim, a prevenção de acidentes seja garantida com total sucesso.

A colaboração dos trabalhadores é fundamental para o sucesso da implementação do programa, pois eles são peças chaves para o bom funcionamento do PPRA. Sem o comprometimento de todos com a busca pela prevenção de acidentes é prejudicada e torna-se mais difícil de ser atingida.

\section{Análise Preliminar de Risco (APR)}

A Análise Preliminar de Risco, mais comumente conhecida como APR, é uma ferramenta muito útil na prevenção de acidentes, pois sua aplicação permite que sejam avaliados e controlados de forma preliminar os riscos de acidentes possíveis de ocorrerem no ambiente de trabalho, reduzindo-se a probabilidade dos mesmos ocorrerem.

\section{Discussão e Resultados}

Muitas são as perdas causadas pela a ocorrência de um acidente do trabalho, de acordo com o quadro 5, Barbosa Filho (2001) destaca as seguintes como as principais no sentido econômico:

A Organização Internacional do Trabalho estima

Quadro 5. Principais perdas econômicas provocadas por acidentes do trabalho

\begin{tabular}{|c|l|}
\hline PERDA & \multicolumn{1}{c|}{ PERDAS ECONÔMICAS } \\
\hline $\begin{array}{c}\text { a) Perdas por danos a } \\
\text { pessoas: }\end{array}$ & $\begin{array}{l}\text { •por indenizações a trabalhadores e a terceiros; } \\
\text {-pelo transporte (terrestre e aéreo, se for o caso) e cuidados médicos, inclusive hospitalares, cirúrgicos, } \\
\text { internação e com medicamentos, durante todo o período demandado, devidos ao(s) acidentado(s); }\end{array}$ \\
\hline $\begin{array}{c}\text { b) Perdas relativas a } \\
\text { aspectos legais: }\end{array}$ & $\begin{array}{l}\text { •honorários advocatícios, de gestores e de peritos em causas trabalhistas; } \\
\text { •encargos empregatícios: horas-extras, adicional de férias, aposentadorias e demais despesas refle- } \\
\text { xas } \\
\text { •encargos e sanções referentes a infrações relativas à saúde e segurança do trabalho; } \\
\text { •seguros públicos e privados; } \\
\text { •perdas previstas em demais contratos etc.; }\end{array}$ \\
\hline $\begin{array}{c}\text { c) Perdas em equipa- } \\
\text { mentos: }\end{array}$ & $\begin{array}{l}\text { •Resultantes de danos causados à maquinaria, ferramentas, gabaritos de produção e instalações (rela- } \\
\text { tivos, por exemplo, ao reparo, substituição e perda de valor de revenda ou residual); }\end{array}$ \\
\hline d) Perdas materiais: & $\begin{array}{l}\text { •danos ocorridos com as matérias-primas, em processamento, produtos acabados ou semiacabados; } \\
\text { •perdas de fluidos (óleo, água, vapor etc.) ou outros produtos de uso indireto na produção; } \\
\text { •por danos à edificação ou a componentes de sua estrutura; }\end{array}$ \\
\hline
\end{tabular}


Quadro 5 (cont.). Principais perdas econômicas provocadas por acidentes do trabalho

\begin{tabular}{|c|c|}
\hline PERDA & PERDAS ECONÔMICAS \\
\hline \multicolumn{2}{|l|}{ e) Perdas produtivas: } \\
\hline e.1) No aspecto técnico: & $\begin{array}{l}\text {-perda de uniformidade e o aumento da possibilidade de erros na produção; } \\
\text { •redução no rendimento produtivo; } \\
\text { •atrasos na produção e na entrega de produtos; }\end{array}$ \\
\hline $\begin{array}{l}\text { e.2) No aspecto hu- } \\
\text { mano: }\end{array}$ & $\begin{array}{l}\text { •baixa no moral, na condição física e psíquica dos trabalhadores; } \\
\text {-possíveis dificuldades quando da reinserção laboral do acidentado - necessidade de reabilitação ou } \\
\text { de mudança de função - assegurada por lei ao trabalhador;36 } \\
\text {-perdas familiares decorrentes dos cuidados com o acidentado (por exemplo, alguém ter que deixar } \\
\text { de trabalhar por certo período de tempo, com a respectiva perda dos rendimentos daquele familiar) e/ } \\
\text { ou a redução do rendimento familiar em termos econômicos (quando comparados os rendimentos do } \\
\text { indivíduo ativo face ao seguro-acidente ou aposentadoria), que atinge, dessa forma, a própria empresa } \\
\text { e outras empresas, vez que decresce o poder aquisitivo em sentido amplo; }\end{array}$ \\
\hline $\begin{array}{l}\text { f.1) Pelo(s) } \\
\text { envolvido(s) no aci- } \\
\text { dente: }\end{array}$ & $\begin{array}{l}\text {-parada de produção e a demanda de um período de afastamento - ainda que mínimo - para a retoma- } \\
\text { da do ritmo normal da condição de trabalho; }\end{array}$ \\
\hline $\begin{array}{l}\text { f.2) Por parte dos com- } \\
\text { panheiros de trabalho: }\end{array}$ & $\begin{array}{l}\text {-para socorro direto e indireto ao(s) envolvido(s); } \\
\text {-para informarem-se do ocorrido; } \\
\text {-por razões emocionais e de outras naturezas; }\end{array}$ \\
\hline $\begin{array}{l}\text { f.3) Por parte dos supe- } \\
\text { riores hierárquicos: }\end{array}$ & $\begin{array}{l}\text {-para socorro direto e indireto ao(s) envolvido(s); } \\
\text {-para restabelecer a normalidade e a ordem, bem como para } \\
\text { - a elaboração de relatos sobre o ocorrido; } \\
\text {-para selecionar e treinar o(s) substituto(s), quando necessário; } \\
\text {-para investigar o acidente e elaborar estratégias que visem evitar a reincidência do evento; } \\
\text {-para atender o(s) acidentado(s) e seus familiares; } \\
\text {-para acompanhar procedimentos legais e assessorar as decisões da empresa referentes a estes; } \\
\text {-pela redução da atenção ao desenvolvimento regular das atividades desempenhadas pelos demais } \\
\text { trabalhadores; }\end{array}$ \\
\hline g) Perdas de mercado: & $\begin{array}{l}\text {-responsabilidade civil por fato do produto e outras atribuições da empresa em relação ao Código de } \\
\text { Defesa do Consumidor; } 37 \\
\text { •indenizações e penalidades pelo não cumprimento de acordos estabelecidos; } \\
\text { •devoluções e reclamações dos clientes, quando não houver a perda da aceitação do produto por estes } \\
\text { ou a busca por outros fabricantes e/ou fornecedores. }\end{array}$ \\
\hline
\end{tabular}

que há uma perda de até $4 \%$ do PIB devido às doenças e acidentes relacionados ao trabalho, e que os ambientes de trabalho inadequados provocam uma perda de produtividade muito grande, além de provocar também grandes perdas humanas.

Baseando-se nestes dados, é nítida a grande necessidade da prevenção de acidentes na indústria. Com a implementação de uma boa política de prevenção de acidentes, tem-se como resultado uma melhora significa na produtividade e rentabilidade da empresa.

\section{Conclusão}

Conforme visto neste trabalho, os acidentes registrados no setor industrial representam mais de $60 \%$ do total de acidentes do trabalho no Brasil, com isso se verifica a grande necessidade de investimentos na área de saúde e segurança.

Diante disso, conclui-se através da revisão bibliográfica realizada neste trabalho que a prevenção de acidentes do trabalho na indústria é fator chave para o sucesso de uma organização, pois quando a segurança dos colaboradores é colocada em primeiro lugar existem muitos benefícios que podem ser obtidos.

Aumento de produtividade, melhora da imagem da empresa e trabalhadores mais motivados são uns dos principais benefícios a se destacar com a implementação de uma boa política de prevenção de acidentes.

As empresas só têm a se beneficiar com a prevenção de acidentes, pois reduzindo o número de acidentes também se reduz as perdas humanas e financeiras, e consequentemente, aumenta-se a lucratividade.

\section{Referências}

Asfahl, C. R. (2005). Gestão de segurança do trabalho e saúde ocupacional. (1a ed.). São Paulo: Reichmann \& Autores Editores. 
Barbosa Filho, A. N. (2018). Segurança do Trabalho e Gestão Ambiental. 5.

ed. (5a ed.). São Paulo: Editora Atlas.

Brasil. (1º de mai de 1943). Decreto-Lei n 5.452. Consolidação das Leis do Trabalho.

Brasil. (08 de jun de 1978). Portaria n. 3.214. Aprova as Normas

Regulamentadoras do Capítulo V do Título II da Consolidação das Leis do Trabalho.

Brasil. (2017). Fonte: AEAT - Anuário Estatístico de Acidente de Trabalho: http://sa.previdencia.gov.br/site/2018/09/AEAT-2017.pdf

Enit. (2011). Norma Regulamentadora $N^{\circ} 5$. Comissão Interna de Prevenção de Acidentes. Fonte: https://enit.trabalho.gov.br/portal/images/Arquivos SST/SST_NR/NR-05.pdf

Enit. (2017). Norma Regulamentadora $\mathrm{N}^{\circ}$ 9. Programa de Prevenção de Riscos Ambientais. Fonte: https://enit.trabalho.gov.br/portal/images/ Arquivos_SST/SST_NR/NR-09.pdf

Hobsbawm, E. J. (2012). A Era das Revoluções: 1789-1848 (10a ed.). São Paulo: Paz e Terra.

Oit. (26 de nov de 2019). Organização Internacional do Trabalho. Fonte: https://bit.ly/35Tsh1w

Osst. (26 de nov de 2019). Observatório de Segurança e Saúde no trabalho. Fonte: https://smartlabbr.org/sst/localidade/3300308?dimensao=despesa Sell, I. (2002). Projeto do Trabalho Humano. Florianópolis: UFSC. 